\title{
Mariposas de Rossi López Huelva o como atrapar el vuelo de la belleza en vidrio'
}

Por Anastasio Lovo

Recibido: 18.11.2015/ Aprobado: 19.11.2015

Los monos trenzaban un hilo interminablemente erótico en las riberas de la aurora, derribando muros de polen y espantando el vuelo violeta de las mariposas de Muzo.

\section{Pablo Neruda}

Canto General

Si hay una maestra en el mundo contemporáneo del delicado y difícil arte de realizar vitrales, falsos vitrales y mosaicos, esa es la nicaragüense Rossi López Huelva. Dueña de una óptica capaz de plasmar lo real maravilloso en una síntesis visual extraordinaria, con una propuesta cromática singular y con un sentido libérrimo de la composición de las formas artísticas, Rossi López Huelva, ha logrado la hazaña artística de captar en sus obras la tórrida belleza de los trópicos americanos. Trópicos de suyos barrocos, de suyos mágicos, de suyos lúdicos, olorosos, fragorosos, exultantes, sensuales y eróticos.

El día de hoy, en ocasión de la jornada en celebración del cuadragésimo octavo o cuarenta y ocho aniversario de fundación de la Universidad Politécnica de Nicaragua, esta Alma Mater, se engalana con una exposición falsos vitrales móviles de la maestra Rossi López Huelva. Como podremos observar cuando disfrutemos la exposición, esta vez Rossi López nos ha traído, La Leyenda de la mujer dormida.

Es decir, la leyenda de la creación de dos de los volcanes más bellos de México: el Popocatépetl y el Iztaccíhualt. Leyenda que nos habla del amor eterno de un

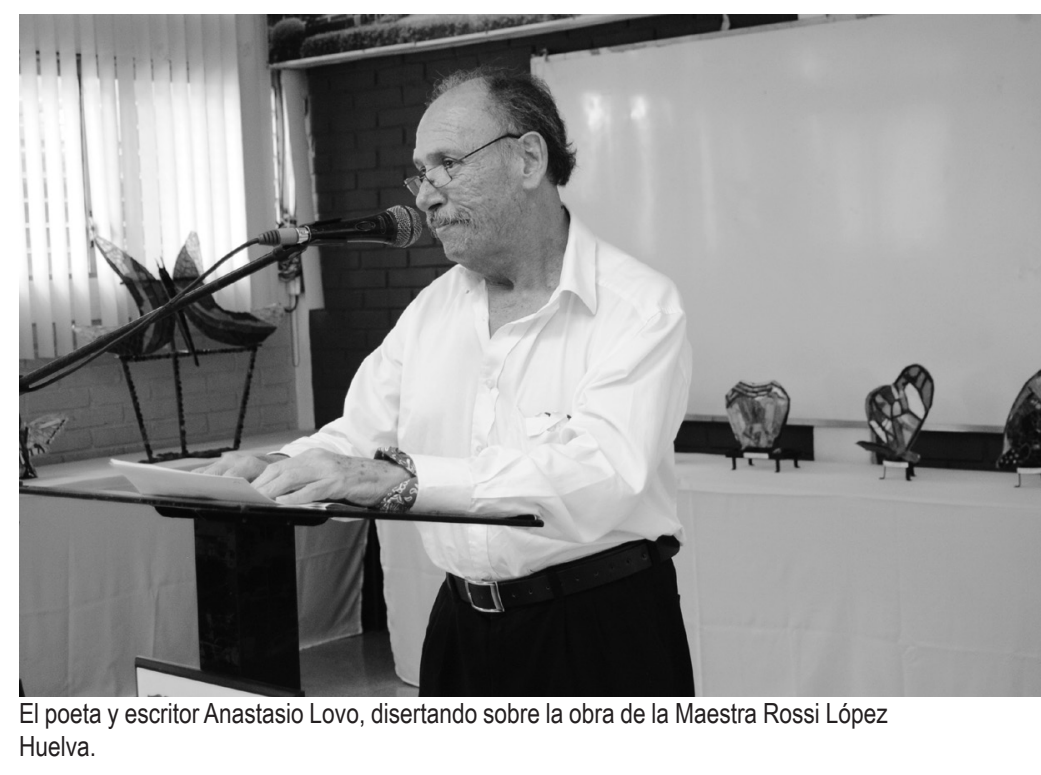

guerrero por una princesa. Un guerrero que para honrar a su princesa muerta por una mentira, le construye con diez grandes cerros una tumba colosal compuesta por el complejo geológico Popocatépelt e Iztaccíhualt.

Es decir, lo que Rossi plasma con singular magisterio es uno de los paisajes naturales (landscape) y colosales de América y lo mágico de una leyenda de creación de una bella geología cuya piedra angular es el amor humano. El color utilizado con propiedad en las formas adecuadas nos connotan todo el misterio y la sensualidad que circunda el sueño de una mujer. La mujer dormida.

Pero de una mujer dormida se escapan sueños en forma de mariposas, escribiría García Márquez, cuando la naturaleza que crea y rodea a esa mujer dormida es la bella, sensual, feraz y feroz naturaleza americana. Mariposas que se alimentan del sueño real de una

1 Palabras ofrecidas por el Poeta Anastasio Lovo en la exposición de vitrales titulada "Butterflies" de la Maestra Rossi López Huelva, realizada por el Instituto "Martin Luther King" en el marco de la celebración del 48 aniversario de fundación de la Universidad Politécnica de Nicaragua (UPOLI).

2 Poeta y crítico de arte nicaragüense. 
poderosa creadora como Rossi López Huelva que al objetivar éstas en vidrios cromáticos logra atrapar la belleza en su vuelo.

Las mariposas son flores que vuelan y todo hacen excepto cantar, según el poeta norteamericano Robert Frost. Igualmente las flores son mariposas posadas. Pero ambas mariposa y flor cantan sus colores. Y es a este concierto polifónico de colores, a esta fiesta cromática sin par, a la que nos invitan las 33 mariposas que Rossi ha detenido en su vuelo o ha captado en su pose serena para que las disfrutemos y las adquiramos en esta exposición.

Las mariposas pertenecen al orden de los lepidópteros y son una bella lección de la capacidad de sobrevivencia de una especie delicada y frágil. Para sobrevivir a sus depredadores estos insectos han desarrollado con su belleza, color y forma, una extraordinaria capacidad de mimetismo, camuflarse en el medio ambiente como otro animal más grande. Las mariposas poseen una vital capacidad de cripsis, capacidad de camuflarse con su entorno natural: una mariposa pretende ser a ojos de sus depredadores una flor más del jardín.
Con una capacidad de síntesis hija de cubismo y con una capacidad de aplicación cromática caudataria del expresionismo o simplemente proveniente de nuestra naturaleza y cultura barrocas latinoamericanas, Rossi López Huelva atrapa en sus mariposas: el mínimo cárdeno del seno rosáceo de la aurora, los ocres oros de un bosque otoñal, los grandes ojos en las alas que engañan al depredador, la oposición cromática de muerte y vida en un rojinegro que se precipita en picada en su vuelo, el azul cielo mar que queda en las alas de una morfa, una mariposa de Muzo de esas que cantaba Neruda, los verdes clorofílicos y delicados...

Todo el color posible, Rossi López Huelva, Maestra del Vitral, lo ha logrado plasmar, estructurar en estas bellas obras de arte que recrean la belleza de la naturaleza americana. Esa belleza que en vuelo y pose de mariposas logra captar para nosotros, a costa de mucho sacrificio, fuerza y esfuerzo nuestra querida artista plástica Rossi López Huelva. Gracias.

Managua, 18 de noviembre de 2015

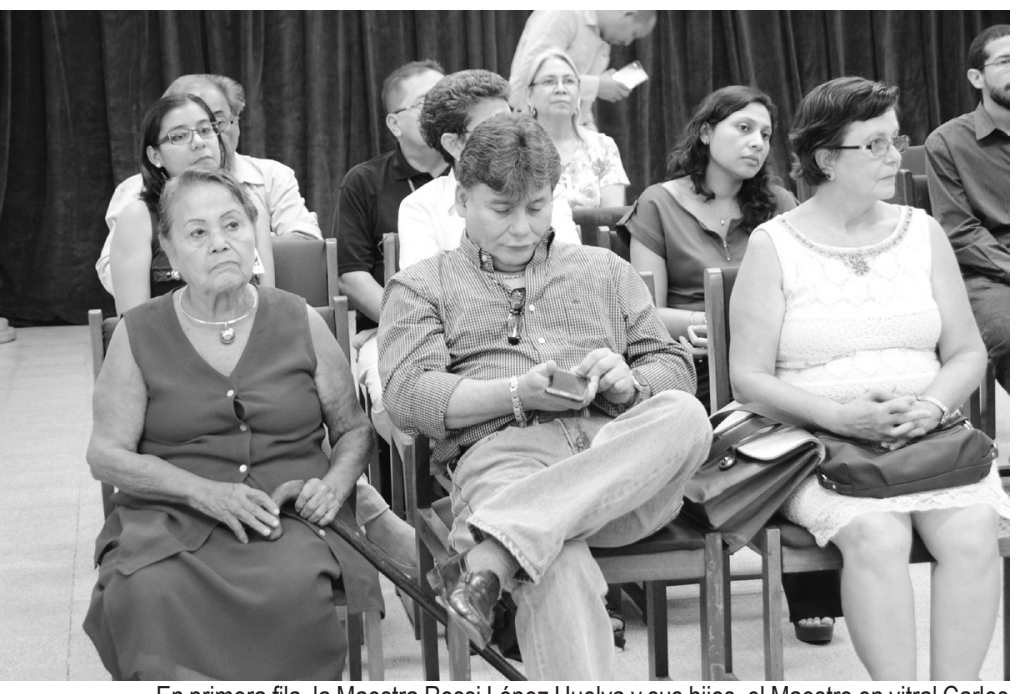

En primera fila, la Maestra Rossi López Huelva y sus hijos, el Maestro en vitral Carlos López y la educadora, MSc. Giovanna Daly.

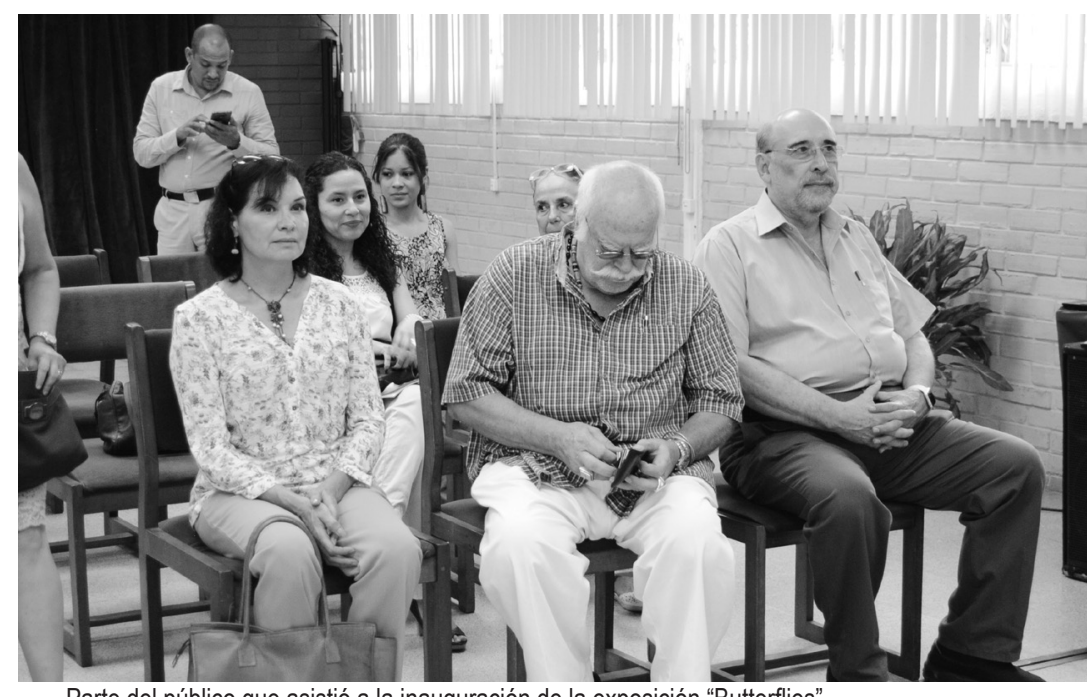

Parte del público que asistió a la inauguración de la exposición "Butterflies". 